\title{
La regulación municipal de las viviendas de uso turístico: soluciones a través del urbanismo ${ }^{1}$
}

\section{Local regulation of short-term rentals: solutions through urban planning}

\author{
Josep M. Aguirre i Font \\ Universitat de Girona (España) \\ ORCID: http://orcid.org/0000-0003-1797-893X \\ josepmaria.aguirre@udg.edu
}

\section{NOTA BIOGRÁFICA}

Profesor agregado interino de Derecho administrativo de la Universitat de Girona y colaborador docente de la Universitat Oberta de Catalunya. Doctor en Derecho por la Universitat de Girona y premio extraordinario de doctorado en Derecho, Economía y Empresa 2013. Sus publicaciones se centran en el Derecho ambiental desde cuatro líneas de investigación: la ordenación del litoral, el urbanismo, el ruido y el cambio climático.

\section{RESUMEN}

El auge de las viviendas turísticas en España, a lo largo de la última década, ha puesto el fenómeno en el centro del debate público y ha llevado a muchos municipios a plantearse la necesidad de ordenarlos o limitarlos. Este artículo analiza, a través de la óptica de la jurisprudencia, las experiencias acumuladas de los últimos años mediante la legislación turística, las ordenanzas municipales y la planificación urbanística. El análisis de los diferentes instrumentos normativos, y singularmente los ejemplos de Barcelona y Bilbao, nos permite extraer algunas conclusiones útiles y al mismo tiempo proponer soluciones normativas óptimas para abordar este fenómeno, compatibilizando el derecho a la ciudad o a una vivienda digna y la libertad de prestación de servicios.

\section{PALABRAS CLAVE}

Economía colaborativa; viviendas de uso turístico; ordenanzas municipales; planeamiento urbanístico; directiva de servicios.

\begin{abstract}
The boom in short-term rentals in Spain, over the last decade, has put the phenomenon at the center of public debate and has led many municipalities to consider the need to organize or limit them. This article analyzes, through the eyes of jurisprudence, the experiences accumulated in recent years through tourism legislation, local regulation and urban planning. The analysis of the different regulatory instruments, and particularly the examples of Barcelona and Bilbao, allows us to draw some useful conclusions and at the same time propose optimal regulatory solutions to address this phenomenon, making the «right to the city» or the «right to housing» compatible with the freedom to provide services.
\end{abstract}

\section{KEYWORDS}

Sharing economy; short-term rentals; local regulation; urban planning; directive of services.

1 Este artículo se ha redactado en el marco del proyecto "El urbanismo y sus instrumentos de incidencia positiva en el medio ambiente y en el cambio climático" (DER2017-85624-C3-1-R) dirigido por el Dr. Joan M. Trayter Jiménez y financiado por el Ministerio de Economía y Competitividad. 
REALA. Nueva Época - N. ${ }^{15}$, abril 2021 - ISSN: 1989-8975 - DOI: https://doi.org/10.24965/reala.i15.10916 - [Págs. 24-41]

La regulación municipal de las viviendas de uso turístico: soluciones a través del urbanismo Josep M. Aguirre i Font

\begin{abstract}
SUMARIO
INTRODUCCIÓN: LA NECESIDAD DE REGULAR O LIMITAR LA ACTIVIDAD DE LAS VIVIENDAS TURÍSTICAS. 1. EL RÉGIMEN DE INTERVENCIÓN ADMINISTRATIVA EN LAS VIVIENDAS DE USO TURÍSTICO: LOS LIIMITES DE LA NORMATIVA TURÍSTICA PARA INTRODUCIR RESTRICCIONES AL USO DE VIVIENDA TURÍSTICA. 2. LAS LIMITACIONES URBANÍSTICAS Y LAS VIVIENDAS TURÍSTICAS DESDE LA ÓPTICA DE LA JURISPRUDENCIA DEL TRIBUNAL DE JUSTICIA DE LA UNIÓN EUROPEA. 3. LA LIMITACIÓN DE LA IMPLANTACIÓN DE VIVIENDAS TURÍSTICAS MEDIANTE ORDENANZA MUNICIPAL: UNA VÍA INEFICAZ. 4. LA REGULACIÓN URBANÍSTICA DE LAS VIVIENDAS TURÍSTICAS: LOS EJEMPLOS DE BARCELONA Y BILBAO. 4.1. BARCELONA: EL PLAN ESPECIAL URBANÍSTICO DE REGULACIÓN DE ESTABLECIMIENTOS DE ALOJAMIENTO TURÍSTICO (PEUAT). 4.2. BILBAO: LA MODIFICACIÓN DEL PLAN GENERAL DE ORDENACIÓN URBANA. A MODO DE CONCLUSIÓN: LA NECESIDAD DE ARTICULAR UN RÉGIMEN DE AUTORIZACIÓN DE LAS VIVIENDAS TURÍSTICAS DE NATURALEZA TEMPORAL Y QUE GARANTICE LA LIBRE CONCURRENCIA. REFERENCIAS BIBLIOGRÁFICAS.
\end{abstract}

\title{
INTRODUCCIÓN: LA NECESIDAD DE REGULAR O LIMITAR LA ACTIVIDAD DE LAS VIVIENDAS TURÍSTICAS
}

La pandemia mundial de COVID-19 ha puesto de nuevo el derecho a la vivienda y las dificultades de la administración pública para garantizarlo en el centro del debate público. Un problema, el de acceso a la vivienda, que a medio plazo se verá agravado por la recesión económica y la pérdida de puestos de trabajo que pueden incrementar el sobrecoste de la vivienda y las tasas de carencia de hogar en el conjunto de la Unión Europea².

En el caso español los déficits históricos en materia de vivienda social, y singularmente la inexistencia de un parque público de vivienda social ${ }^{3}$, ponen el foco de nuevo en la necesidad de garantizar que el suelo vinculado a un uso residencial se ponga al servicio de la efectividad del derecho a disfrutar de una vivienda digna y adecuada que exige el art. 3.4 del Texto refundido de la Ley de Suelo y Rehabilitación Urbana (TRLSRU).

El problema del acceso a la vivienda en el mercado, agravado por la inexistencia de unas políticas públicas que ofrezcan alternativas a los sectores sociales con mayores dificultades, se hace singularmente más problemático en las ciudades con mayor presión turística, donde una parte de la oferta habitacional se ha desplazado hacia el mercado de las viviendas de uso turístico, lo que ha conllevado un encarecimiento del alquiler tradicional (Roca, 2016, 40-48; Duatis et al., 2016, 50-56; García et al., 2020, 15).

A pesar de que el número de viviendas turísticas, sobre el total del parque construido, constituye aún un porcentaje ínfimo en el conjunto del Estado -321.000 viviendas, que representan un 1,3\% del parque construido (INE, 2020)-, su incremento a lo largo de los últimos años ha vuelto a poner en el debate público la necesidad de regular su implantación. Sin lugar a duda ha contribuido a ello el papel activo de los lobbies turísticos, que ven en las viviendas turísticas una competencia desleal a la actividad hotelera (Exceltur, 2015, 72). Los datos corroboran el incremento de la presión de la vivienda turística en el mercado de alojamientos turísticos, pues el potencial de plazas de vivienda turística en España, de 1,6 millones, ha llegado a acercarse al total de plazas hoteleras existentes, de 1,9 millones, e incluso superar la capacidad media de plazas disponibles, que es de 1,5 millones.

La distribución de las viviendas turísticas, sin embargo, no es homogénea. El 76,8\% de las viviendas turísticas se encuentran en la franja costera, y solo el 23,2\% están situadas en zonas interiores. Tampoco por comunidades la distribución es igual, pues tres de ellas -Andalucía, Cataluña y la Comunidad Valenciana- acaparan prácticamente tres quintas partes del total del parque estatal. La concentración de viviendas turísticas es singularmente importante en las ciudades de Madrid y Barcelona, que aglutinan el 10,6\% del total -más de 120.000 plazas entre las dos-, particularmente en determinados barrios del centro.

La concentración excesiva de viviendas turísticas influye en el precio del mercado de alquiler tradicional, conlleva en muchos casos problemas asociados de convivencia en los bloques plurifamiliares, donde

2 Resolución del Parlamento Europeo, de 21 de enero de 2021, sobre el acceso a una vivienda digna y asequible para todos $(2019 / 2187(\mathrm{INI}))$

3 Un total de 0,9 viviendas por cada 100 habitantes según Eurostat, lo que representa un $2,5 \%$ del total del parque de viviendas principales. 
conviven viviendas habituales y turísticas, y también problemas en entornos urbanos que se degradan por la presión turística y el fenómeno de la turistificación (Socías, 2018, 134, 137 y 2020, 227-230; Boix, 2018, 382-383).

Todo ello ha llevado a muchos municipios a plantearse la necesidad de regular o limitar la actividad de las viviendas turísticas mediante instrumentos propios -sea mediante ordenanzas o regulación urbanística-. En este artículo analizaremos las capacidades y los límites de la regulación municipal para abordar el fenómeno de las viviendas turísticas. Para ello estudiaremos en primer lugar el régimen de intervención administrativa en las viviendas de uso turístico a través de la normativa turística autonómica, para adentrarnos posteriormente en los mecanismos normativos para introducir limitaciones. La voluntad del trabajo es discernir, a partir de las diferentes experiencias y de la jurisprudencia recaída, cuáles son los vehículos normativos óptimos para abordar este fenómeno.

\section{EL RÉGIMEN DE INTERVENCIÓN ADMINISTRATIVA EN LAS VIVIENDAS DE USO TURÍSTICO: LOS LÍMITES DE LA NORMATIVA TURÍSTICA PARA INTRODUCIR RESTRICCIONES AL USO DE VIVIENDA TURÍSTICA}

El crecimiento exponencial de las viviendas turísticas en España a lo largo de los últimos 10 años ha llevado aparejado el desarrollo de una normativa específica que las ha regulado. La necesidad de abordar esta realidad ya se puso de manifiesto en el preámbulo de la Ley $4 / 2013$, de 4 de junio, de medidas de flexibilización y fomento del mercado del alquiler de viviendas, que por vez primera excluía el alojamiento privado para el turismo de la Ley de Arrendamientos Urbanos (LAU) y lo derivaba a su normativa sectorial. En la Ley se motivaba la exclusión por el hecho de que este uso «podría estar dando cobertura a situaciones de intrusismo y competencia desleal, que van en contra de la calidad de los destinos turísticos» (Guillén, 2015, 115).

A partir de ahí las comunidades autónomas han ido desarrollando, mediante sus competencias en materia turística, marcos normativos propios para regular dicha actividad (Herrero, 2017, 156-160; Román Sánchez et al., 2017, 403-412), sometiendo la misma a regímenes de comunicación previa o declaración responsable con unas exigencias mínimas vinculadas, esencialmente, al respeto de la normativa de vivienda, urbanística o de propiedad horizontal, lo que a efectos prácticos condicionaba la apertura de la actividad de vivienda de uso turístico fundamentalmente al hecho de disponer de cédula de habitabilidad, que los usos de la zona no prohibiesen su implantación y que la misma tampoco estuviera prohibida por los estatutos de la comunidad de propietarios.

A pesar de que algunas de las normativas autonómicas, como la de Madrid $^{4}$, habían explorado mayores exigencias o limitaciones al desarrollo de las viviendas turísticas mediante la normativa sectorial -como la exigencia de visado colegial, la limitación mínima de noches o la inscripción previa al registro- el Tribunal Supremo (TS), en la Sentencia 1741/2018, de 10 de diciembre, aplicando las previsiones de la Directiva 2006/123/CE y su normativa de desarrollo, ha ido limitando estas previsiones por no estar justificadas en términos de necesidad y proporcionalidad, lo que ha llevado a adaptar esa normativa, eliminando las restricciones de la normativa turística ${ }^{5}$.

También Canarias, con una importantísima planta hotelera, intentó establecer limitaciones al desarrollo de las viviendas turísticas en su regulación ${ }^{6}$. Por un lado, en relación con el procedimiento, intentó desvirtuar la declaración responsable condicionando el inicio efectivo de la actividad al hecho de que el Cabildo Insular entregara a la persona titular de la vivienda cierta documentación -lo que fue anulado por diversas sentencias $^{7}$ del Tribunal Superior de Justicia (TSJ) de la comunidad, al entender que se estaba desnaturalizando la declaración responsable y sometiendo la actividad a un control administrativo previo-. Por el otro, en relación con el ámbito de aplicación de la normativa, Canarias pretendía excluir las viviendas de uso turístico justamente de las zonas más turísticas, con el argumento de carácter económico que las viviendas turísticas no compitiesen con el resto de los establecimientos de alojamiento -previsión anulada por el TSJ de las

4 Decreto 79/2014, de 10 de julio, del Consejo de Gobierno, por el que se regulan los apartamentos turísticos y las viviendas de uso turístico de la Comunidad de Madrid.

5 Decreto 29/2019, de 9 de abril, del Consejo de Gobierno, por el que se modifica el Decreto 79/2014, de 10 de julio, por el que se regulan los apartamentos turísticos y las viviendas de uso turístico de la Comunidad de Madrid.

6 Decreto 113/2015, de 22 de mayo, por el que se aprueba el Reglamento de las viviendas vacacionales de la Comunidad Autónoma de Canarias.

7 STSJ de las Islas Canarias de 21 de marzo de 2017 y 5 de julio de 2017. 
Islas Canarias ${ }^{8}$ y confirmada en casación por el TS-. En este sentido, el TS, en la STS 1766/2018, de 27 de noviembre, afirmó que este tipo de limitaciones son contrarias al principio de libertad de empresa del artículo 38 CE y a la libre prestación de servicios de la Directiva 2006/123/CE, pues intentar favorecer la oferta de productos de alojamiento tradicionales resulta contrario a los principios de necesidad y proporcionalidad enunciados en el artículo 5 de la Ley 20/2013, de 9 de diciembre, de garantía de la unidad de mercado. En la misma regulación también se anuló la pretensión del Gobierno canario de prohibir la cesión por habitaciones, al entender que se trataba de una medida contraria a los principios de regulación recogidos en el artículo 4 de la Ley $2 / 2011$, de 4 de marzo, de economía sostenible, en particular del principio de necesidad y proporcionalidad, y que no existía ninguna prohibición en la LAU -SSTS 25/2019 y 26/2019, de 15 de enero-. En términos idénticos, la limitación del alquiler de habitaciones también fue anulada del Decreto gallego por la STS 1401/2019, de 21 de octubre, por no apreciarse razones de interés general que la justificasen.

Sí que recibió el aval de la jurisprudencia del TS el Decreto de la Junta de Castilla y León, que no introducía limitaciones al ejercicio de la actividad de vivienda turística, pero exigía determinados requisitos. Según la STS 1237/2019, de 24 de setiembre, los elementos temporales referidos a la habitualidad de la actividad y a la duración del hospedaje -para determinar la aplicación de la normativa sectorial- no contravienen la directiva de servicios, pues la simple exclusión de la normativa sectorial únicamente supone que el ejercicio de la actividad es libre. En la misma sentencia se concluyó que la exigencia de placa identificativa, de unos estándares de habitabilidad o de un servicio de asistencia telefónica durante 24 horas tampoco puede considerarse desproporcionada, pues protege los derechos de los consumidores y usuarios. Algunos de los mismos requisitos, también incorporados en la normativa gallega, fueron de nuevo avalados en la STS 1401/2019, de 21 de octubre, por idénticos motivos.

Sea como fuere, las pocas limitaciones en la normativa turística no han sido obstáculo para que los ayuntamientos intentaran desarrollar marcos normativos propios para limitar la implantación de viviendas turísticas, fuese mediante ordenanza municipal o mediante regulación urbanística de los usos del suelo. De hecho, algunas normativas sectoriales ya prevén abiertamente esta posibilidad, como la Ley de turismo de Cataluña, que faculta al Ayuntamiento de Barcelona -en el marco de su régimen especial, establecido por la Ley 22/1998, de 30 de diciembre, de la Carta municipal de Barcelona- a regular las actividades de alojamiento turístico en viviendas de uso turístico y en hogares compartidos mediante ordenanzas municipales, que pueden establecer requisitos particulares y pueden fijar limitaciones temporales y periodos máximos de vigencia de la habilitación para ejercer estas actividades. También el Decreto gallego que contempla la posibilidad de que los ayuntamientos establezcan limitaciones en lo que respecta al número máximo de viviendas de uso turístico por edificio o por sector -previsión esta última que fue objeto de la STS 625/2020, de 1 de junio, que admitió la legalidad de la cláusula afirmando que no es posible excluir a priori que en un determinado ayuntamiento concurran circunstancias que puedan constituir una razón imperiosa de interés general para limitar el número de viviendas de uso turístico-. De hecho, con carácter más general, las normativas autonómicas contemplan la exigencia de que la actividad de vivienda turística se adecue a las previsiones urbanísticas o de otra normativa sectorial.

Ahora bien, a pesar de estas previsiones, el juego entre la abierta normativa turística y las eventuales exigencias de la normativa sectorial o municipal plantean algunos problemas jurídicos sobre las técnicas utilizadas para introducir las limitaciones en la actividad de viviendas turísticas y los límites de las mismas desde dos perspectivas: la idoneidad de introducir limitaciones mediante ordenanzas o planeamiento urbanístico y los márgenes de las normas para imponer limitaciones a actividades económicas de conformidad con la Directiva 2006/123/CE y la jurisprudencia del Tribunal de Justicia de la Unión Europea (TJUE). Analicémoslos a continuación.

\section{LAS LIMITACIONES URBANÍSTICAS Y LAS VIVIENDAS TURÍSTICAS DESDE LA ÓPTICA DE LA JURISPRUDENCIA DEL TRIBUNAL DE JUSTICIA DE LA UNIÓN EUROPEA}

El debate público en torno a las viviendas turísticas se ha ido reproduciendo a lo largo y ancho de la geografía europea, y singularmente en los municipios con mayor presión turística o dificultades de acceso a la vivienda. Ello, inevitablemente, ha planteado en muchos municipios la búsqueda de soluciones jurídicas para

8 STSJ de las Islas Canarias de 21 de marzo de 2017 y 25 de mayo de 2017. 
limitar la implantación de estas actividades, lo que ha abierto un debate recurrente sobre la adecuación de estas a las reglas de la Directiva 2006/123/CE, sobre el que se ha pronunciado la jurisprudencia del TJUE.

En este sentido, sobre los límites que las normativas urbanísticas pueden introducir en determinadas actividades y su relación con la directiva de servicios, ha tenido ocasión de pronunciarse el TJUE en su Sentencia de 30 de enero de 2018 (Asuntos C-360/15, C-31/16) afirmando que «la Directiva 2006/123 no se opone a que el acceso a una actividad de servicios o su ejercicio se supedite al respeto de un límite territorial de esta índole, siempre que se cumplan las condiciones de no discriminación, necesidad y proporcionalidad enunciadas en su artículo 15, apartado 3» (apartado 132). En el caso en cuestión, el TJUE valoraba si un plan urbanístico podía preservar la habitabilidad del centro de la ciudad de un municipio y evitar la existencia de locales desocupados en zona urbana en interés de una buena ordenación del territorio; la conclusión de la Gran Sala fue que «el objetivo de protección del entorno urbano puede constituir una razón imperiosa de interés general que justifique un límite territorial como el controvertido en el litigio principal» (apartado 135).

Esta sentencia habilitaba al planificador urbanístico a imponer restricciones territoriales para el acceso o ejercicio de una actividad económica siempre que estuvieran justificadas por razones de interés general y cumpliesen los principios de no discriminación, necesidad y proporcionalidad (Otero, 2020, 290).

Pero el precedente jurisprudencial más cercano y relevante, para la materia que nos ocupa, lo tenemos en la Sentencia del TJUE de 22 de setiembre de 2020 en los asuntos acumulados C-724/18 Cali Apartments y C-727/18 Procureur général près la cour d'appel de Paris y ville de Paris. En la sentencia el TJUE analiza la adecuación del Código de la Construcción y de la Vivienda francés en relación con el régimen de autorización de las viviendas turísticas y la posibilidad de condicionar la misma a una compensación consistente en la transformación simultánea en vivienda de un inmueble que tenga otro uso.

En primer lugar, la Gran Sala determina que la Directiva 2006/123/CE se aplica a la actividad de alquiler de viviendas turísticas, efectuada de forma reiterada por periodos de tiempo breves, con independencia de su carácter profesional o no. No solo esto, sino que la propia sentencia dispone que la regulación de las viviendas turísticas no constituye una normativa aplicable a cualquier persona -sino solamente a los arrendadores de viviendas turísticas- y en consecuencia queda fuera de las exclusiones previstas para las normativas generales en materia de ordenación del territorio o urbanismo. Se trata de un pronunciamiento nuclear y que había sido cuestionado recurrentemente por la jurisprudencia española, que en muchos casos entendía, como veremos, que la planificación urbanística de las viviendas turísticas se mantenía fuera del ámbito de aplicación de la Directiva de Servicios.

Partiendo de la anterior premisa, la Gran Sala examina la normativa francesa afirmando que la autorización previa para el alquiler de viviendas turísticas constituye un «régimen de autorización» de conformidad con la Directiva y por ello debe cumplir las condiciones previstas en los artículos 9.1 y 10.2 de la misma. En este sentido, el TJUE juzga si el objetivo de la normativa, de dar respuesta al deterioro de las condiciones de acceso a la vivienda y al aumento de las tensiones en los mercados inmobiliarios para garantizar el derecho a una vivienda digna, constituye una razón imperiosa de interés general. Su conclusión en este extremo es positiva, al afirmar que el «Tribunal de Justicia ya ha reconocido que las exigencias de la política de vivienda de protección oficial y de lucha contra la presión inmobiliaria, en particular cuando un mercado concreto experimenta una escasez estructural de viviendas y una densidad de población especialmente alta, pueden constituir razones imperiosas de interés general» ${ }^{9}$.

En segundo lugar, el TJUE entra a valorar si la medida acordada se puede conseguir mediante una medida menos restrictiva. Aquí la Gran Sala aprecia que la normativa resulta circunscrita solamente al arrendamiento turístico, que se excluyen las que constituyen residencia principal del arrendador y que tiene un alcance geográfico restringido a unos pocos municipios densamente poblados que experimentan tensiones del mercado de alquiler de inmuebles como consecuencia del alquiler vacacional. Así mismo, el TJUE descarta que los controles a posteriori permitan frenar de manera inmediata y eficaz la rápida transformación de viviendas turísticas que tienen importantes impactos en el mercado de alquiler tradicional. Por todo ello concluye que la medida es proporcionada al objetivo perseguido.

Entrando en la condiciones del artículo 10.2, la Gran Sala considera justificados y proporcionados los criterios de la normativa francesa de que se arriende «de forma reiterada y durante breves períodos de tiempo a clientes de paso que no fijan en él su domicilio» o la posibilidad de «fijar condiciones a la vista de

9 Véanse en este sentido, en particular, las sentencias de 1 de octubre de 2009, Woningstichting Sint Servatius, C-567/07, EU:C:2009:593, apartado 30, y de 8 de mayo de 2013, Libert y otros, C-197/11 y C-203/11, EU:C:2013:288, apartados 50 a 52. 
objetivos de diversidad social y en función de las características de los mercados locales de la vivienda y de la necesidad de no agravar la escasez de viviendas, acompañándolas, si fuera necesario, de una obligación de compensación en forma de transformación accesoria y concomitante en viviendas de inmuebles con otro uso», con la salvedad de que tales condiciones de concesión sean conformes con los requisitos establecidos por el propio artículo 10.2 y que tal obligación pueda satisfacerse en condiciones transparentes y accesibles.

Todo ello da un importante margen de discrecionalidad a las autoridades locales francesas, y en consecuencia al resto de estados miembros, para entrar a regular las actividades de alquiler de turismo vacacional dentro de los límites de la propia Directiva, de conformidad con la interpretación de la Gran Sala.

Partiendo de esta premisa, analicemos a continuación la idoneidad de los diferentes instrumentos normativos utilizados por los municipios -ordenanzas e instrumentos de planeamiento- para regular y limitar la implantación de las viviendas de uso turístico a partir de la jurisprudencia de los TSJ y del propio TS.

\section{LA LIMITACIÓN DE LA IMPLANTACIÓN DE VIVIENDAS TURÍSTICAS MEDIANTE ORDENANZA MUNICIPAL: UNA VÍA INEFICAZ}

A pesar de que la normativa autonómica se ha visto condicionada estos últimos años por una jurisprudencia reacia a introducir limitaciones a la actividad de las viviendas turísticas, esto no ha sido obstáculo para que muchos municipios intentaran abordar la regulación y limitación de esta actividad mediante sus propios instrumentos normativos. Aunque, como veremos en este artículo, el instrumento natural para ordenar o limitar usos son los planes urbanísticos, no son pocos los ejemplos de ordenanzas municipales que también lo han intentado.

Las técnicas normativas utilizadas por muchas de estas ordenanzas son diversas: establecimiento de un régimen de inspección obligatorio para todos los que presenten una declaración responsable; incorporación de mayores exigencias para desarrollar la actividad de las previstas en la normativa autonómica; zonificación del municipio y limitación del porcentaje de viviendas turísticas; obligación de mantener una distancia mínima entre viviendas turísticas, o limitación de su implantación al cumplimiento de parámetros urbanísticos.

Grosso modo, el conjunto de técnicas utilizadas por las ordenanzas municipales se resume en dos grupos: 1) las que configuran un régimen jurídico que desvirtúa la declaración responsable o la comunicación previa, y 2) las que introducen directamente regulaciones propias del planteamiento urbanístico -zonificación, limitación por distancias, parámetros urbanísticos, etc.-.

En relación con la modificación del régimen de declaración responsable o la comunicación previa, observamos cómo algunos ayuntamientos, sin habilitación legal para ello, exigen la presentación de documentación no prevista en la normativa autonómica o bien establecen un sistema de control obligatorio, en un plazo breve, para todos los que formalicen una declaración responsable o la comunicación previa, equivalente a un régimen de licencia. A pesar de tratarse de técnicas abiertamente ilegales, hay pocas sentencias que entren a controlarlas, probablemente porque en estos casos no impiden el ejercicio de la actividad y en consecuencia hay menos litigiosidad. Destaca, sin embargo, la Sentencia 3142/2020, de 16 de julio, del TSJ de Cataluña (TSJC), por la que la Sala anula diversos artículos de una ordenanza municipal que pretendía establecer un control obligatorio de todas las declaraciones responsables formalizadas mediante la exigencia de presentación de documentación que verificase el cumplimiento de los datos y circunstancias en el plazo de un mes desde la presentación de la declaración responsable. Ello convertía de facto el régimen de declaración responsable en un régimen de autorización, pues la no superación de la inspección obligatoria conllevaba la extinción del título habilitante.

Más importancia parecen tener, por número y relevancia jurídica, los múltiples intentos de muchos ayuntamientos de introducir, mediante ordenanza, limitaciones propias del planeamiento urbanístico a la actividad de las viviendas turísticas (ACCO, 2014, 4-9). De todas ellas, el uso de la zonificación o la exigencia de determinados parámetros urbanísticos -como las características de la vivienda o su ubicación- son los más recurrentes. A diferencia de las técnicas que modificaban el régimen de declaración responsable o comunicación previa, algunas de las previsiones de estas ordenanzas son claramente limitativas del uso de vivienda turística, sin que en las mismas se justifiquen las limitaciones en términos de necesidad y proporcionalidad. En la mayoría de los casos estas ordenanzas, que como desarrollaremos a continuación no tienen encaje en nuestro marco normativo, no han sido objeto de control jurisdiccional, sea por su reciente aprobación, sea porque su adopción en pequeños municipios simplemente no ha sido impugnada. 
Sobresale, en esta regulación municipal, un precedente relevante: la ordenanza municipal reguladora del uso urbanístico de vivienda turística y alquiler de habitaciones en vivienda habitual para uso turístico de Donostia ${ }^{10}$ (Atxukarro, 2017, 1.598-1.604 y 2019, 2-6), anulada por la Sentencia 1/2020, de 9 de enero, del TSJ del País Vasco.

La Ordenanza de Donostia, aprobada en 2018, suponía un desarrollo del Plan General de Ordenación Urbana (PGOU) de conformidad con la previsión de su artículo 8.4, que permitía reajustar y complementar la sistematización de usos del PGOU y abría la posibilidad de que el Ayuntamiento, mediante ordenanza, tipificara y regulara los usos no incluidos en el PGOU por la analogía de sus efectos urbanísticos con los de otros usos (AVC, 2018, 8).

En este contexto, la ordenanza desarrollaba el concepto y los requisitos del uso de vivienda turística, definía las condiciones del inmueble, lo sistematizaba como un uso terciario de naturaleza hotelera, lo que imponía condiciones importantes a la implantación en las plantas altas -limitando el uso a edificios enteros o bien a plantas bajas o primeras plantas- $y$, sobre todo, definía una zonificación de la ciudad en que prohibía totalmente el uso en la zonas saturadas (Parte Vieja) y lo circunscribía a las otras zonas por las condiciones mencionadas.

La Sentencia del TSJPV 1/2020, de 9 de enero, que ya es firme, declara la nulidad de la Ordenanza y del artículo 8.4 del PGOU en que se fundamentaba, sin entrar en la regulación concreta, pues se limita a afirmar que la legislación urbanística del País Vasco «no contempla las Ordenanzas como instrumentos normativos para regular, modificar, complementar, desarrollar, o reajustar los usos urbanísticos». No es posible, en consecuencia, modificar la regulación de usos urbanísticos sin modificar el planeamiento urbanístico, pues las ordenanzas son meramente complementarias de la ordenación urbanística.

Parece obvio que, si la sentencia vasca excluye la utilización de las ordenanzas municipales complementarias de la ordenación urbanística para ordenar usos, excluya con carácter general la utilización de cualquier ordenanza municipal con independencia de su naturaleza jurídica para ordenar usos urbanísticos. De hecho, esta conclusión, a nuestro entender, es perfectamente extrapolable al conjunto del Estado, pues la definición del uso del territorio y del suelo de acuerdo con el interés general es un monopolio de la ordenación territorial y urbanística, de conformidad con lo que dispone el artículo 4, de carácter básico, del TRLSRU. Por lo tanto, no es posible, fuera de sus instrumentos normativos -los planes- entrar a regular usos del suelo.

\section{LA REGULACIÓN URBANÍSTICA DE LAS VIVIENDAS TURÍSTICAS: LOS EJEMPLOS DE BARCELONA Y BILBAO}

Descartada la utilización de las ordenanzas municipales para introducir limitaciones adicionales que desvirtúen la declaración responsable o la comunicación previa, o el uso de estas para regular los usos del suelo, centrémonos en las regulaciones urbanísticas.

Como se ha expuesto, la ordenación del uso del suelo constituye un monopolio de la ordenación territorial y urbanística, y es el entorno normativo idóneo para valorar y adaptar cualquier regulación limitativa de la actividad de vivienda turística. Pero al mismo tiempo la aplicación de la técnica urbanística a priori, como apunta Estanislao Arana $(2018,14-18)$, puede plantear dudas en relación con la libertad de presentación de servicios y su adecuación a la propia Directiva de Servicios.

Las regulaciones urbanísticas adoptadas son diversas: zonificación de la ciudad y definición de incompatibilidad del uso o densidad máxima permitida; prohibición de compatibilidad del uso turístico con el residencial en el mismo inmueble; definición de los estándares de los edificios donde se pueden ubicar las viviendas turísticas; distinción del uso residencial del de naturaleza turística; prohibiciones totales de viviendas turísticas y prohibiciones relativas; regulaciones que buscan el reagrupamiento de las viviendas o la extinción de títulos, etc.

La jurisprudencia, con carácter general, admite la necesidad de una regulación urbanística que busca en primer término distinguir el uso residencial del turístico (Bauzá, 2018, 318-321), no solo por las importantes implicaciones que puede tener desde la perspectiva del ejercicio del derecho de acceso a la vivienda del artículo 47 de la CE, sino también por las consecuencias que un uso u otro tiene en términos de infraestructuras, servicios, dotaciones y equipamientos, pues parece evidente, como reconocen los tribunales, que no es lo mismo una ocupación temporal que una permanente ${ }^{11}$.

10 BOP de Gipuzkoa de 26 de marzo de 2018.

11 Sentencia del TSJ Andalucía, de 29 de junio de 2015, confirmada por la STS 2318/2016, de 17 de octubre de 2016. 
De hecho, en las recientes SSTS 1550/2020, de 19 de noviembre, y 75/2021, de 26 de enero, el Tribunal advierte sobre los riesgos de la viviendas turísticas y sus consecuencias para la ciudad, su identidad y la vida de los residentes de una manera muy explícita: «en las grandes ciudades, es igualmente posible y previsible llegar a su desertización (gentrificación), en determinados lugares, al alterarse la forma de vida de los residentes habituales, debido a la transformación -de hecho- de un uso tradicional residencial, en otro, pujante y turístico, con todas la consecuencias que de ello se derivan, pues, es evidente que cuando más auténtico es un lugar, a más gente atrae, pero, cuanta más gente atrae, más se diluye su auténtica identidad, y con ello la vida de los residentes habituales del mismo lugar. Es, en síntesis, convertir las ciudades -o las partes esenciales de la mismas- en un a modo de parque temático, en vez de un lugar habitable y de convivencia. La ciudad se convierte en un problema y no en un sistema de solucionar los problemas de sus habitantes.».

Este problema justifica, para el TS, la intervención del planeamiento urbanístico: «Todo ello nos conduce a confirmar la posibilidad -y la necesidad- de intervención municipal en la materia, en uso y ejercicio de la potestad de planeamiento, que cuenta con un claro respaldo y legitimación democrática, y que, además, se nos presenta como realizada por la Administración más cercana al ciudadano, y articulada con un mayor grado de participación y conocimiento de la concreta realidad local.».

Ahora bien, la aplicación concreta de las técnicas urbanísticas para limitar y ordenar las viviendas turísticas, lejos de ser pacífica, ha sido objeto de muchísima controversia jurídica a lo largo de la última década, que ha servido para ir perfilando sus principales características.

Abordamos su estudio, en este artículo, a partir de dos ejemplos de éxito dispar: el primero, la ordenación de Barcelona a través de una regulación singular de los establecimientos de alojamiento turístico mediante un plan especial -anulado por el TSJC- y el segundo, la regulación de Bilbao, con una modificación de su plan general, con el mismo objetivo, pero que cuenta con el respaldo del TSJ del País Vasco (TSJPV) y el TS. Son dos modelos muy ilustrativos de los problemas y retos que ha tenido que abordar el urbanismo para hacer frente al fenómeno de las viviendas turísticas.

\subsection{Barcelona: el plan especial urbanístico de regulación de establecimientos de alojamiento turístico (PEUAT)}

La ciudad de Barcelona tiene, con datos de $2020^{12}$, 9.561 viviendas turísticas legalizadas, que representan un $1,4 \%$ sobre los domicilios existentes y un 1,17\% en relación con el conjunto de viviendas, cifra que creció de forma muy rápida los primeros años de la década pasada (Artigot, 2017, 8 y Cuscó et al., 2015, 11) pero se ha mantenido congelada los últimos años como consecuencia de las limitaciones municipales ${ }^{13}$, y que con toda seguridad la crisis producida por la pandemia de COVID-19 ha hecho disminuir de forma singular ${ }^{14}$.

A pesar de ello, algunos estudios apuntan a la existencia de un parque de viviendas turísticas mucho más grande, según datos del INE, la ciudad de Barcelona tenía en agosto de 2020 -en plena pandemia de COVID-19, y sin apenas turismo- un total de 17.280 viviendas turísticas anunciadas a través de plataformas digitales (INE, 2020).

Todo ello explica la cruzada del Ayuntamiento de Barcelona en la última década para regular y limitar la implantación de viviendas turísticas, que se ha desarrollado en paralelo a un proceso de liberalización de la normativa turística de la Generalitat en relación con las viviendas turísticas: si en 2010 en Cataluña se exigía licencia municipal ${ }^{15}$, en 2012 se pasó a pedir una comunicación previa muy simplificada ${ }^{16}$, y a partir de 2015 -hasta la actualidad- solamente es necesaria una mera declaración responsable ${ }^{17}$.

12 Datos de la Memoria del PEUAT-2021.

13 En 2010 había 824 viviendas turísticas legalizadas, que aumentaron hasta las 9.606 en 2014 , una cifra prácticamente idéntica a la actual, de 9.561 en 2020.

14 La patronal del sector calculaba, en mayo de 2020, que un $40 \%$ de las viviendas turísticas se habían reconvertido al alquiler tradicional (http://bit.ly/3pCeJkG; última visualización, 20 de enero de 2021), y esta cifra ya había aumentado al $62 \%$ en setiembre de 2020 (http://bit.ly/3dwkHAY; última visualización, 20 de enero de 2021).

15 Artículo 6 del Decreto 64/2010, de 9 de noviembre, de regulación de las viviendas de uso turístico. turístico.

16 Artículo 68 del Decreto 159/2012, de 20 de noviembre, de establecimientos de alojamiento turístico y de viviendas de uso

17 Artículo 13.a) y anexo I de la Ley 16/2015, de 21 de julio, de simplificación de la actividad administrativa de la Administración de la Generalidad y de los gobiernos locales de Cataluña y de impulso de la actividad económica, y artículo 32 y anexo de la Ley $18 / 2020$, de 28 de diciembre, de facilitación de la actividad. Los requisitos de las viviendas turísticas se regulan en los artículos $221-1$ y $221-2$ del Decreto 75/2020, de 4 de agosto, de turismo de Cataluña. 
Aunque en Barcelona la regulación del alojamiento turístico se remonta a la modificación de su Plan General en 1989 -para regular las nuevas zonas de dotación hotelera con ocasión de los Juegos Olímpicos de 1992- los intentos de frenar el fenómeno de las viviendas turísticas empiezan en 2010, con el Plan especial de establecimientos de concurrencia pública, hotelería y otras actividades en Ciutat Vella ${ }^{18}$. Un instrumento de planeamiento que exigía que las viviendas turísticas, en esa zona de la ciudad, se ubicaran en edificios sin viviendas - de primera o segunda residencia- y que las nuevas solicitudes de autorización se acompañasen, por parte del solicitante, de la renuncia previa del titular de una autorización existente.

EI TSJC entra en el fondo de aquella primera regulación a través de diferentes sentencias ${ }^{19}$, pero solo en relación con los hoteles (no las viviendas turísticas), entendiendo que la regulación de usos turísticos del Plan especial queda fuera del ámbito de la Directiva de Servicios y validando la regulación de distancias o densidades de los establecimientos, que entiende razonables para evitar la concentración de establecimientos en un mismo lugar. En cambio, las sentencias sí anulan la exigencia que para obtener una nueva licencia se requiera previamente la renuncia de una anterior, al entender que desde la perspectiva del titular de la licencia representa «una ilícita intromisión tendente a la exigencia de extinción de derechos adquiridos regladamente con arreglo a la normativa anterior», y desde la perspectiva de que quienes no sean titulares de ninguna licencia supone literalmente una exclusión del derecho de solicitarla y obtenerla. Estas primeras coordenadas jurisprudenciales marcarán el futuro de la regulación de usos turísticos en Barcelona.

En 2013 se opera una modificación del Plan especial de establecimientos de concurrencia pública, hotelería y otras actividades en Ciutat Vella ${ }^{20}$. Ahora la nueva regulación, en lugar de exigir una renuncia, condiciona la implantación de una nueva vivienda de uso turístico a la baja de otra licencia otorgada, exigiendo igualmente que la baja se aportase con la solicitud de la nueva licencia. El cambio terminológico intenta evitar su anulación judicial, pues el Ayuntamiento de Barcelona entiende que la baja, en lugar de renuncia, no obliga a renunciar a ningún derecho adquirido, pero sí sirve para controlar la densidad máxima establecida por la norma. No solo esto; la regulación de 2013 también incorpora, mediante la disposición adicional primera, un plazo máximo de 6 años para que las viviendas turísticas existentes se agrupen en edificios enteros donde no haya viviendas principales o secundarias, o bien se extingan.

En el enjuiciamiento del Plan especial de 2013, el TSJC entra a analizar la regulación de las viviendas turísticas en diferentes sentencias ${ }^{21}$. La Sala entiende como legítimo el interés y objetivo del Plan de compatibilizar el uso turístico y otros con el uso de vivienda por la población residente «mediante el bloqueo del número total de plazas existentes, estableciendo como presupuesto, para el emplazamiento de una nueva actividad, la baja de otra actividad». También entiende que la regulación se encuentra fuera del ámbito de aplicación de la Directiva de Servicios. Ahora bien, igual que con la regulación de 2010, la exigencia de presentar una baja para obtener una licencia es anulada con idénticos motivos a los expuestos anteriormente. Las sentencias recaídas también cuestionan la legalidad de la disposición que obliga a reagrupar viviendas turísticas o extinguirlas, al entender que no es posible extinguir títulos habilitantes sin indemnización previa, y la anulan.

La jurisprudencia del TSJC marca el campo de juego: es posible y legítimo entrar a limitar las viviendas de uso turístico sin infringir la Directiva de Servicios, pero ello no debe comportar la exigencia a los nuevos solicitantes de aportar la renuncia o la baja de anteriores titulares. Tampoco es admisible extinguir los títulos habilitantes existentes sin indemnización previa.

En 2016 estas previsiones específicas para Ciutat Vella fueron derogadas y sustituidas por una regulación global en toda la ciudad del uso de vivienda turística. El Plan especial urbanístico de regulación de las viviendas turísticas ${ }^{22}$ incorpora las previsiones singulares de Ciutat Vella y extiende, mediante la configuración de la densidad máxima de viviendas turísticas admisibles por zonas, la prohibición de otorgar nuevos títulos habilitantes a otras zonas de la ciudad sin que se produjera con carácter previo una baja, prohibiendo incluso el otorgamiento de nuevos títulos a las zonas más céntricas de la ciudad. Junto a estas limitaciones,

18 Pla especial d'establiments de concurrència pública, hoteleria i altres serveis del Districte de Ciutat Vella (BOP de Barcelona de 30 de setiembre de 2010).

19 Entre otras, sentencias 357/2014, de 12 de junio; 199/2014, de 2 de abril; 431/2014, de 16 de julio, y 620/2014, de 5 de noviembre.

20 Modificació del Pla especial d'establiments de concurrència pública, hoteleria i altres activitats a Ciutat Vella (BOP de Barcelona de 16 de setiembre de 2013).

21 Entre otras, sentencias 323/2017, de 29 de mayo; 371/2017 de 12 de junio; 73/2018, de 25 de enero, y 616/2019, de 28 de junio

22 Pla especial urbanístic per a la regulació dels habitatges d'ús turístic a la ciutat de Barcelona (BOP de Barcelona de 21 de abril de 2016). 
se añade también una condición adicional de densidad máxima por isla de casas, en algunos casos, y la exigencia de que el edificio donde se pretende ubicar la vivienda turística no estuviera destinado a vivienda el 1 de julio de $2015^{23}$.

A efectos prácticos, la regulación suponía de facto una suspensión de otorgamiento de nuevos títulos habilitantes en toda la ciudad, en una clara voluntad de limitar la actividad en lugar de ordenarla o intentar configurarla, como se expresaba con todas las letras en la memoria del documento urbanístico: «La consecuencia de esta acción estratégica es la de no permitir ningún tipo de aumento de las viviendas turísticas concedidas hasta la fecha. La creciente proliferación de las viviendas turísticas en la ciudad y las dificultades para hacer compatible esta actividad con las dinámicas urbanas propias de los barrios y sus residentes así lo aconsejan y piden.».

Se trataba de una regulación temporal, pues el propio documento se tramitó en paralelo al Plan especial urbanístico de regulación de establecimientos de alojamiento turístico (PEUAT), y contemplaba en su disposición final única que la regulación quedaría sustituida por este último en el momento en que fuera ejecutivo. Y efectivamente fue así: en marzo de 2017 se publicaba el PEUAT ${ }^{24}$, que recogía igualmente la voluntad de bloquear el aumento de las viviendas turísticas (Rodríguez Font, 2016, 172-173; ACCO, 2017, 1-13; Román Márquez, 2018, 22-39).

A pesar de la corta vida del Plan especial urbanístico de regulación de las viviendas turísticas, esto no fue obstáculo para la interposición de diversos recursos contenciosos que años después de que el plan perdiera vigencia terminaron de nuevo en sentencias que anulaban el mismo. El TSJC estimó la necesidad de resolver sobre el fondo, a pesar de la pérdida de vigencia, por la eventualidad de que una posible anulación del PEUAT resucitase la vigencia del Plan especial urbanístico de regulación de las viviendas turísticas de 2016.

En este sentido, el TSJC dictó entre primavera y verano de 2019 una decena de sentencias ${ }^{25}$ que partían de la misma premisa sobre la que se había construido la jurisprudencia de los planes de usos de Ciutat Vella: el Plan especial se encontraba fuera del ámbito de aplicación de la Directiva, la planificación no afecta al acceso de una actividad de servicios o su ejercicio, sino que se trata de normas relativas a la ordenación del territorio o al urbanismo. Pero, además, añadía la Sala, «nos hallamos en presencia de "razones imperiosas de interés general", tal como éstas han sido definidas por el Tribunal de Justicia de la Unión Europea, más si reparamos en que la motivación de la figura de planeamiento impugnada ofrece unos propósitos que persiguen configurar un determinado modelo de ciudad».

De hecho, el TS, en la reciente Sentencia 75/2021, de 26 de enero, concluye que la regulación del Plan especial urbanístico de regulación de las viviendas turísticas en relación con la zonificación, que limita el crecimiento de las viviendas turísticas, está plenamente justificada por «la Administración que mejor conoce la ciudad de Barcelona» y por ello, de conformidad con la jurisprudencia del TJUE, debe «excluirse la vulneración, tanto de la Directiva 2006/123, como de la legislación interna que la traspone».

Esto no fue obstáculo para que el TSJC anulara, en una primera sentencia (302/2019, de 4 de abril), las exigencias que el Plan introducía en relación con la tramitación del título habilitante -respuesta en el plazo máximo de 30 minutos a cualquier requerimiento municipal, satisfacer gastos a la administración municipal, depósitos o avales, acuerdo de la junta de propietarios y de nuevo depósitos y avales- que excedían de las previsiones de la normativa turística catalana. A criterio de la Sala, aquella regulación turística no tenía ninguna cobertura legal en un plan urbanístico. También anuló la previsión de la normativa que pretendía acreditar el uso del edificio, a 1 de julio de 2015, a partir de la simple alta formal del mismo en el catastro. Así mismo, anuló una previsión según la cual las viviendas dadas de baja por expediente sancionador implicaban una reducción de la densidad máxima de las viviendas turísticas previstas en el Plan, pues a partir de una simple sanción administrativa de naturaleza temporal se imponían consecuen-

23 El 1 de julio de 2015 era la fecha de suspensión de licencias acordada por el Ayuntamiento de Barcelona para elaborar el planeamiento urbanístico necesario para regular adecuadamente la implantación de alojamientos turísticos en la ciudad (BOP de Barcelona de 2 de julio de 2015).

24 Pla Especial Urbanístic per a la regulació dels establiments d'allotjament turístic, albergs de joventut, residències col·lectives d'allotjament temporal i habitatges d'ús turístic a la ciutat de Barcelona (BOP de Barcelona de 27 de enero de 2017).

25 Sentencias de la Sala Contencioso-Administrativa del TSJC 302/2019, de 4 de abril; 450/2019, de 21 de mayo; 451/2019, de 21 de mayo; 472/2019, de 28 de mayo; 473/2019, de 28 de mayo; 544/2019, de 12 de junio; 659/2019, de 2 de julio; 684/2019, de 9 de julio; 719/2019, de 15 de julio, y 752/2019, de 29 de julio. Buena parte de ellas incorporan la jurisprudencia fijada por la Sala en la Sentencia 628/2018, de 3 de julio, que daba conformidad a la Modificación del Plan General Metropolitano en cuanto a la regulación de las viviendas de uso turístico en el municipio de Badalona. 
cias indefinidas en el planeamiento. Finalmente, también declaró la nulidad de un artículo que limitaba el régimen de las edificaciones en situación de disconformidad más allá de las previsiones de la legislación urbanística.

Estas tesis se confirmaron en las sentencias posteriores, que también acabaron anulando, en la 472/2019, de 28 de mayo, la previsión que se había incorporado al Plan especial de Ciutat Vella de 2013, que daba 6 años para reagrupar las viviendas de uso turístico en un único edificio o extinguirlas. Entendió la Sala, como ya había apuntado en 2017 en relación con el Plan especial de Ciutat Vella de 2013, que esta previsión debía ser indemnizada.

Las sentencias del TSJC daban validez de nuevo a la regulación de la densidad propuesta, y por vez primera también a la exigencia de que los nuevos títulos se condicionaran a la materialización de bajas, que ahora ya no debían aportarse por el solicitante, sino que este elemento debía constatarse directamente por la administración a los efectos de acreditar la densidad.

Finalmente, el Plan especial urbanístico de regulación de las viviendas turísticas, fue anulado en su integridad por la Sentencia 544/2019, de 12 de junio, por la falta de un buen estudio económico y financiero que previese «los medios con que cuenta la administración para afrontar el coste de los beneficios fiscales, subvenciones, ayudas económicas, indemnizaciones expropiatorias, adquisiciones de bienes de particulares objeto de catalogación o del ejercicio de los derechos de tanteo o retracto que se prevén», y singularmente, como justificaba la sentencia, cuando el propio documento de planificación preveía la extinción de títulos por falta de adecuación al Plan.

Las lecciones parecen claras: es posible limitar el crecimiento de las viviendas turísticas mediante la técnica de la densidad urbanística, pero no modificar la regulación turística o extinguir títulos sin previa indemnización. Y en cualquiera de los casos la planificación urbanística, de una innegable importancia económica, debe contar con un buen estudio económico y financiero.

A pesar de ello, como veremos a continuación, el PEUAT aprobado antes de las citadas sentencias reiteró los errores del Plan especial urbanístico de regulación de las viviendas turísticas y terminó con la misma suerte: anulado (Rodríguez Florido, 2020, 277-294).

EI PEUAT mantiene, en esencia, la misma regulación que el Plan especial urbanístico de regulación de las viviendas turísticas aprobado solo unos meses antes, motivo por el cual el TSJC, cuando dictaminó sobre el mismo ${ }^{26}$-en paralelo a las sentencias del Plan especial urbanístico de regulación de las viviendas turísticas- volvió sobre los viejos argumentos: el Plan se encontraba fuera del ámbito de la Directiva 2006/123/ CE y la figura que buscaba preservar determinadas zonas de las secuelas de los usos turísticos estaba suficientemente justificada; no es posible extinguir títulos habilitantes sin indemnización previa, y sobre todo, el informe de sostenibilidad económica que incorporaba el Plan no contenía ninguna evaluación económica y financiera de las actuaciones a desarrollar. Destaca como novedad la anulación también de la exigencia de que para implantar nuevas viviendas turísticas se requiera una autorización del $100 \%$ de la propiedad del edificio, regulación de naturaleza civil impropia de un plan urbanístico.

En este contexto, las experiencias del Ayuntamiento de Barcelona de los últimos años para limitar las viviendas turísticas, aunque valientes, innovadoras y apuntadas en la dirección correcta, han resultado ineficaces por las debilidades de los propios instrumentos de planeamiento. A pesar de ello, el pasado 29 de enero de 2021 el Ayuntamiento de Barcelona volvió a aprobar inicialmente el nuevo Plan Especial Urbanístico para la regulación de los establecimientos de alojamiento turístico (PEUAT-2021) ${ }^{27}$.

La aprobación del nuevo PEUAT 2021 no se realiza en sustitución del PEUAT 2017, pues las sentencias que lo anularon no son todavía firmes ${ }^{28}$, sino como una revisión del PEUAT 2017. Aun así, la memoria no ignora las sentencias dictadas por el TSJC, al afirmar que la jurisprudencia de la Sala de lo Contencioso-Ad-

26 Sentencias del TSJC 438/2019, de 21 de mayo; 466/2029, de 27 de mayo; 764/2019, de 29 de julio; 765/2019, de 29 de julio; 769/2019, de 29 de julio; 880/2019, de 7 de octubre; 881/2019, de 7 de octubre; 912/2019, de 15 de octubre; $939 / 2019$, de 22 de octubre; $1001 / 2019$, de 11 de noviembre; 1022/2019, de 18 de noviembre; 1024/2019, de 18 de noviembre; $1043 / 2019$, de 25 de noviembre; 1091/2019, de 9 de diciembre; 1093/2019, de 9 de diciembre; 1094/2019, de 9 de diciembre; 1095/2019, de 9 de diciembre; 1099/2019, de 9 de diciembre; 1100/2019, de 9 de diciembre; 1101/2019, de 9 de diciembre; 1130/2019, de 17 de diciembre, y $1134 / 2019$, de 17 de diciembre.

27 Aprobación inicial del Pla especial urbanístic per a la regulació dels establiments d’allotjament turístic, albergs de joventut, habitatges d'ús turístic, llars compartides i residències col·lectives docents d'allotjament temporal (BOP de Barcelona de 1 de febrero de 2021).

${ }_{28}$ EI TS no ha admitido a trámite los recursos de casación, pero algunas de las sentencias se encuentran pendientes del recurso de casación autonómico. 
ministrativo avala la planificación municipal y al mismo tiempo corrige algunos de los aspectos cuestionados, como la falta de evaluación económica y financiera o la anulación de títulos habilitantes sin indemnización.

EI nuevo PEUAT 2021, que ahora inicia la tramitación, incorpora algunos elementos novedosos en relación con la anterior normativa, como la prohibición de viviendas turísticas en las viviendas unifamiliares o la prohibición general de implantación de viviendas compartidas previstas por primera vez en la normativa turística catalana desde agosto de $2020^{29}$.

Desaparece, en cambio, uno de los elementos que había caracterizado la normativa reguladora de las viviendas turísticas en Barcelona desde el 2010: la exigencia de que las viviendas se ubicaran en edificios enteros sin viviendas principales o secundarias. El motivo es que la nueva normativa no puede obligar a los propietarios a obtener el aval del $100 \%$ de los propietarios, ni tampoco al reagrupamiento de viviendas turísticas bajo amenaza de extinción del título. A pesar de ello, la normativa mantiene dos elementos que de facto imposibilitan el desarrollo de nuevas viviendas turísticas: la prohibición de situar viviendas turísticas en edificios que tuvieran viviendas principales o secundarias a 1 de julio de $2015 \mathrm{y}$, sobre todo, las reglas de densidad, que impiden nuevos títulos habilitantes en la zona centro de la ciudad, y únicamente permiten abrir nuevas viviendas turísticas en otras zonas de la ciudad si previamente se da una baja de un título habilitante existente.

EI PEUAT 2021 refuerza la exigencia de informe previo para la apertura de una nueva vivienda turística, el mecanismo mediante el cual la administración verifica si el censo de viviendas turísticas permite un eventual crecimiento en la zona en que se solicita. La nueva regulación dispone que la emisión favorable del informe garantiza «la reserva de plazas en el emplazamiento concreto y que este emplazamiento no se puede ver afectado por la apertura de nuevos establecimientos o la ampliación de plazas de establecimientos existentes que superen la densidad máxima de plazas en el área determinada según criterios radiales o lineales durante un plazo de seis meses a contar desde la fecha de notificación del informe previo». Así mismo, se dispone que «durante la vigencia de un informe previo no se podrá solicitar ningún otro informe previo en relación con el mismo emplazamiento, excepto que se solicite una ampliación de la reserva de plazas previamente efectuada».

El informe, un documento preceptivo y vinculante ya previsto actualmente en el PEUAT 2017, constituye de facto una autorización administrativa encubierta, como apunta Gabriel Doménech $(2018,70)$, al tratarse de un acto expreso previo e imperativo para poder desarrollar la actividad.

Ahora la nueva regulación va un paso más allá en la configuración de este mecanismo y no solo se articula como una auténtica autorización administrativa, sino también como un mecanismo de patrimonialización de derechos, pues la emisión del informe no solo implica la reserva del derecho en relación con el solicitante, sino que bloquea la posibilidad que nadie más lo solicite durante un plazo mínimo de seis meses. El citado plazo se interrumpe por múltiples motivos, entre ellos: la tramitación de un plan especial durante un máximo de 9 meses; durante la tramitación de licencias de obras mayores y comunicados diferidos de obras; durante el plazo de inicio y ejecución de las obras y sus prórrogas, y durante el plazo de 3 meses más para presentar la comunicación con certificado previo.

Todo ello conllevará que cualquier solicitud de informe puede llegar a bloquear durante muchos meses, o incluso años, la posibilidad de solucionar nuevos informes en el mismo emplazamiento, lo que a efectos prácticos supone articular un obstáculo real al desarrollo de nuevas actividades, y por lo tanto se configura como una limitación contraria a la Directiva 2006/123/CE de servicios en el mercado interior.

EI PEUAT 2021 articula, pues, un régimen jurídico que va mucho más allá de la mera declaración responsable prevista en la normativa turística catalana para exigir, además, una autorización de naturaleza urbanística -mediante informe preceptivo y vinculante- que implica una reserva de la plaza frente a otros operadores, es decir, comporta que haya una limitación numérica de las autorizaciones disponibles.

En este contexto es importante recordar que la limitación del número de autorizaciones -una posibilidad prevista legalmente por una razón imperiosa de interés general ${ }^{30}$ exige dos condiciones básicas ${ }^{31}$ que el PEUAT 2021 no cumple: a) El procedimiento de concesión por las Administraciones Públicas garantizará el cumplimiento de los principios de publicidad, objetividad, imparcialidad, transparencia y concurrencia com-

29 Decreto 75/2020, de 4 de agosto, de turismo de Cataluña

30 Artículo 11.1.b de la Directiva 2006/123/CE y 8.1 de la Ley 17/2009, de 23 de noviembre, sobre el libre acceso a las actividades de servicios y su ejercicio.

31 Artículo 12 de la Directiva 2006/123/CE y artículo 8.2 de la Ley 17/2009, de 23 de noviembre, sobre el libre acceso a las actividades de servicios y su ejercicio. 
petitiva; y b) La autorización que se conceda tendrá una duración limitada y proporcionada atendiendo a las características de la prestación del servicio y no dará lugar a un procedimiento de renovación automática ni conllevará, una vez extinguida la autorización, ningún tipo de ventaja para el prestador cesante o para personas especialmente vinculadas a él.

Es igualmente muy cuestionable la prohibición absoluta en toda la ciudad del alquiler de habitaciones en viviendas compartidas por el titular de la misma vivienda. Se justifica la prohibición en la memoria por el hecho de que esta modalidad de alojamiento puede desequilibrar la oferta existente ya cubierta con las actuales viviendas turísticas, y que además es de muy difícil control, al requerir en todos los casos el auxilio judicial para acceder a las viviendas. Ahora bien, la prohibición absoluta parece ignorar la jurisprudencia del TS, que anuló previsiones idénticas en la normativa canaria y gallega, al entender que no concurrían en ellas justificaciones de interés general que permitieran prohibir solo el alquiler de habitaciones en lugar del conjunto de la vivienda vacacional ${ }^{32}$.

Finalmente, el PEUAT 2021 reitera -mediante la disposición adicional quinta- la previsión de que las autorizaciones de viviendas turísticas que causen baja como consecuencia de un procedimiento de disciplina o de comprobación del cumplimiento de los requisitos para el ejercicio de la actividad impliquen un decremento de la densidad máxima de viviendas de uso turístico habilitadas legalmente en la ciudad. Se trata de una previsión anulada por la Sentencia del TSJC 302/2019, de 4 de abril, en que la Sala apuntaba que la «reducción en la densidad máxima de viviendas de usos turísticos impide radicalmente ese uso en el futuro a ese sujeto infractor, lo que patentiza en definitiva una nueva sanción de naturaleza superior sin cobertura legal».

En definitiva, la regulación propuesta, a pesar de encajar desde la perspectiva urbanística de limitación de usos, tiene un mal encaje: 1) en la normativa turística catalana, que solamente exige una declaración responsable para iniciar la actividad; 2) en la Directiva 2006/123/CE y su normativa de desarrollo, al incorporar obstáculos injustificados y no prever mecanismos que garanticen el acceso en términos de igualdad a las autorizaciones existentes; 3 ) en la prohibición absoluta de alquiler de habitaciones prohibida por la jurisprudencia del Tribunal Supremo, y también 4) en la jurisprudencia del TSJC, que anuló el mecanismo de reducción de la densidad como consecuencia de las actividades que causen baja por incumplimiento de la normativa, que ahora se reitera.

\subsection{Bilbao: la modificación del Plan General de Ordenación Urbana}

En el caso de Bilbao, la presión de las viviendas turísticas es menor que en Barcelona. Según el Gobierno Vasco, en 2017 había 620 con título habilitante, lo que supone sólo un 0,38\% del total de viviendas de la ciudad. Con los datos disponibles (INE, 2020), había en Bilbao en agosto de 2020 -en plena pandemia de COVID-19 y sin apenas turismo- 1.005 viviendas turísticas ofertadas en plataformas digitales, lo que representa un $0,6 \%$ del parque total de viviendas. A pesar de ello, la importancia progresiva del turismo en la ciudad, que en los últimos 25 años ha pasado de ser una actividad irrelevante a convertirse en un sector que representa el $5,2 \%$ del PIB, junto con el incremento progresivo de los alojamientos en viviendas turísticas -que el 2016 ya representaban el 8,3\% del total de pernoctaciones- llevaron al Ayuntamiento de Bilbao a impulsar su regulación.

Con ello, según se justificaba en la exposición de motivos, se quería corregir las disfuncionalidades y problemas de convivencia de determinados usos en el mismo edificio, al mismo tiempo que se quería corregir el encarecimiento y escasez de vivienda de alquiler (CNMC, 2018, 54).

La técnica utilizada mantiene similitudes con la utilizada en Donostia -estableciendo requisitos de la ubicación de la vivienda en el edificio y limitaciones en relación con determinadas zonas- pero en lugar de recurrir a la ordenanza municipal lo hace directamente a través de una modificación de su PGOU ${ }^{33}$.

Con carácter general, en el PGOU de Bilbao solo se permite la existencia de viviendas turísticas en la primera planta de los edificios residenciales o en plantas inmediatamente inferiores a las destinadas a vivienda si estas tienen un acceso independiente, y en determinados ámbitos ${ }^{34}$ se reduce esta posibilidad a una

SSTS 26/2019, de 15 de enero, y 1401/2019, de 21 de octubre.

33 Modificación pormenorizada del Plan General de Ordenación Urbana de Bilbao en lo relativo a la regulación del uso de alojamiento turístico (BOP de 13 de febrero de 2018). La Vieja.

34 En los ámbitos del Plan de Rehabilitación del Casco Viejo y del Plan Especial de Rehabilitación y Reforma Interior de Bilbao 
única vivienda turística por edificio. Así mismo, es importante destacar que el PGOU califica las viviendas turísticas dentro del uso de equipamiento y lo diferencia del uso residencial entendido como el alojamiento estable y permanente de las personas.

A nivel de autorización de la actividad, la normativa turística vasca ${ }^{35}$ exige la presentación de una declaración responsable de inicio de la actividad turística ante la Administración turística de Euskadi y la inscripción en el Registro de Empresas y Actividades Turísticas de Euskadi. Así mismo, la normativa exige disponer de licencia de primera ocupación o cédula de habitabilidad y cumplir los requisitos «en materia de infraestructuras, urbanismo, construcción y edificación (...)». Para cumplir con esta exigencia de la normativa, el PGOU exige con carácter previo al inicio de la actividad la obtención de un informe urbanístico de conformidad de la vivienda a la regulación de usos previstos en el mismo.

La regulación del PGOU fue objeto de diversas sentencias ${ }^{36}$ del TSJPV que confirmaron la regulación urbanística en su integridad. Entre todas, destaca la Sentencia 292/2019, de 11 de junio, que desestimaba un recurso de la Comisión Nacional de los Mercados y la Competencia (CNMC), posteriormente también confirmada en casación por la STS 1550/2020, de 19 de noviembre.

En el recurso, la CNMC alegaba que la regulación suponía una barrera de entrada en el mercado del alojamiento turístico, en muchos casos insalvable, que afectaba al $67 \%$ del parque existente; que la exigencia de un informe urbanístico suponía una carga de tipo administrativo, y que las restricciones que imponía a la oferta de viviendas turísticas no encontraban justificación desde el punto de vista de su necesidad y proporcionalidad.

Las sentencias del TSJPV, confirmadas por el TS, entienden que la calificación de las viviendas turísticas como equipamiento es irreprochable, pues necesariamente debe diferenciarse del uso residencial estable y permanente, y es obligación del planificador «calificar el suelo necesario para satisfacer el derecho a la vivienda, y lo ha de hacer dando cumplimiento simultáneo a la red dotacional de sistemas generales y locales (...) ordenación que puede verse alterada y resultar incongruente, si el destino al uso de VUT se deja en manos del mercado, puesto que ello puede suponer el indeseable efecto de su concentración en ámbitos más propicios para la satisfacción del interés de los turistas con desplazamiento de la población residente».

Por todo ello, el TSJPV y el TS entienden que «la ordenación limitativa resulta necesaria por una razón imperiosa de interés general, cual es la preservación del derecho a la vivienda de la población afectada por la ordenación y la protección del entorno urbano». De hecho, el TS en la STS 1550/2020, citando la doctrina establecida en la reciente STJUE de 22 de septiembre de 2020, concluye que «no cabe duda de que el Ayuntamiento de Bilbao se ha situado -al aprobar su norma reglamentaria- en el ámbito del espacio que, con precisión, se describe por la STJUE, alegando y justificando, en un marco de prudencia, equilibrio y proporcionalidad, unas razones como las tomadas en consideración por el Tribunal de Luxemburgo».

En relación con el informe urbanístico, el TSJPV lo justifica al entender que el cambio de uso residencial de la vivienda a equipamiento, de conformidad con la legislación urbanística vasca, está sujeta a licencia y por ello no es disconforme a derecho la exigencia de un informe urbanístico favorable, sin perjuicio de que la normativa turística únicamente exija una declaración responsable.

En conclusión, las sentencias del TSJPV y del TS avalan las restricciones al uso de vivienda turística mediante la técnica de la calificación de esta como equipamiento y defienden la necesidad de establecer limitaciones para proteger el derecho constitucional a la vivienda. Tampoco aprecian disfunción alguna entre la exigencia de la declaración responsable para iniciar la actividad, de conformidad con la normativa turística, y de un informe urbanístico -o una licencia urbanística- para acreditar el cambio de uso de residencial a equipamiento desde la perspectiva de la legislación urbanística.

\section{A MODO DE CONCLUSIÓN: LA NECESIDAD DE ARTICULAR UN RÉGIMEN DE AUTORIZACIÓN DE LAS VIVIENDAS TURÍSTICAS DE NATURALEZA TEMPORAL Y QUE GARANTICE LA LIBRE CONCURRENCIA}

El crecimiento sostenido del turismo en España en los últimos años, sumado a los problemas estructurales de acceso al mercado de la vivienda y a la inexistencia de políticas públicas que contribuyan a resolverlo, ha puesto al fenómeno de la vivienda turística en el centro del debate público en la última década.

35 Decreto 101/2018, de 3 de julio, de viviendas y habitaciones de viviendas particulares para uso turístico.

36 Entre otras, 292/2019, de 11 de junio; 354/2019, de 10 de julio, y 374/2019, de 17 de setiembre. 
A pesar de tratarse de un fenómeno pequeño, que representa poco más del $1 \%$ del parque de viviendas construidas, su incidencia en las ciudades donde desplaza a una parte de la oferta habitacional contribuye al encarecimiento de la oferta de alquiler y puede conllevar otros problemas de convivencia en los inmuebles donde se ubican o en los barrios donde se concentran, lo que ha llevado a muchos municipios a plantearse la necesidad de ordenarlos o limitarlos.

La experiencia de los últimos 10 años para ordenar esta actividad, mediante la legislación turística, las ordenanzas municipales y la planificación urbanística, pero sobre todo gracias a la jurisprudencia del TJUE, el TS y los diferentes TSJ, permite extraer algunas conclusiones útiles y al mismo tiempo proponer soluciones normativas óptimas para abordar este fenómeno.

Por un lado, la normativa sectorial turística no parece el instrumento idóneo para limitar, obstaculizar o directamente prohibir el desarrollo de la actividad de vivienda turística. Hemos de tener en cuenta que prácticamente todas las comunidades, como apunta Gabriel Doménech $(2018,69)$, han sometido esta actividad a comunicación previa o declaración responsable. El motivo parece lógico: no concurren los requisitos de la Directiva de Servicios para exigir una autorización previa. Partiendo de esta premisa, los diferentes intentos de desnaturalizar el régimen de autorización previa o declaración responsable, así como establecer mayores exigencias o limitaciones no justificadas en los términos de necesidad y proporcionalidad de la Directiva de Servicios, han terminado anulados. La misma suerte han tenido los intentos de establecer, mediante normativa turística, la prohibición de la actividad de viviendas turísticas en determinados emplazamientos, o bien prohibir totalmente la cesión de habitaciones.

La normativa sectorial turística permite fijar determinados requisitos o estándares de esta actividad, vinculados por ejemplo a la protección de consumidores y usuarios, y naturalmente condicionar también el desarrollo de la actividad de vivienda turística al respeto del resto de legislación sectorial: esencialmente de vivienda, urbanística y de propiedad horizontal.

Por otro lado, la jurisprudencia del TJUE ha avalado la utilización del planeamiento urbanístico para limitar territorialmente una actividad sin que esto suponga una vulneración de la Directiva de Servicios. De hecho, en la reciente Sentencia de 22 de setiembre de 2020 sobre viviendas turísticas ha admitido que el establecimiento de limitaciones - para garantizar el derecho a una vivienda digna a la población-constituye una razón imperiosa de interés general que justifica su adopción. La Gran Sala avala pues el régimen de autorización de las viviendas turísticas y la posibilitad de condicionar la misma a una compensación consistente en la transformación simultánea en vivienda de un inmueble que tenga otro uso. Ahora bien, lo condiciona en cualquier caso a las condiciones previas de los artículos 9.1 y 10.2 de la Directiva de Servicios.

En este contexto, muchos ayuntamientos a lo largo y ancho del país han intentado en los últimos años, sin habilitación legal previa, introducir regulaciones o limitaciones adicionales a las viviendas turísticas. Las soluciones adoptadas, mediante ordenanzas municipales, de regímenes jurídicos que desvirtúan la declaración responsable o la comunicación previa o bien introducen directamente regulaciones propias del planeamiento urbanístico en la ordenanza, han acabo anuladas cuando han llegado a los tribunales.

La alternativa a esta infructuosa vía, como nos han indicado las recientes SSTS 1550/2020, de 19 de noviembre y 75/2021, de 26 de enero, es la intervención de las viviendas turísticas a través del planeamiento urbanístico, que en palabras del propio Supremo "cuenta con un claro respaldo y legitimación democrática», y además permite «un mayor grado de participación y conocimiento de la concreta realidad local».

Un recorrido a través de las experiencias de planificación urbanística de las viviendas turísticas en Barcelona y Bilbao, y las docenas de pronunciamientos jurisprudenciales sobre los mismos, nos permite radiografiar el estado de la cuestión, extraer algunas conclusiones útiles y proponer algunas mejoras normativas.

El caso de Barcelona, desde la óptica de las sentencias del TSJC, demuestra que es posible y legítimo entrar a limitar o prohibir nuevas viviendas de uso turístico en determinadas zonas mediante la técnica de la zonificación y la densidad, pero no se puede imponer a los solicitantes requisitos desproporcionados -como la exigencia de la renuncia o baja de anteriores titulares- o regulaciones turísticas impropias de la normativa urbanística, ni tampoco pretender la extinción de las viviendas no adaptadas al nuevo planeamiento sin indemnización previa. Sea como fuere, el principal escollo de los planes especiales dictados en los últimos años ha sido esencialmente formal, por la falta de un buen estudio económico y financiero que ha terminado con su anulación.

Ahora el Ayuntamiento de Barcelona está impulsando una nueva planificación de las viviendas turísticas. La nueva regulación plantea algunas dudas importantes, como la prohibición absoluta de alquiler de habitaciones o el refuerzo de un modelo de autorización previa encubierta, mediante un informe previo para la apertura de nuevas viviendas turísticas, que actúa además como un mecanismo limitativo de otras autorizaciones, al bloquear la posibilidad de desarrollar durante meses o años nuevas actividades en el mismo emplazamiento. 
A diferencia de la experiencia de Barcelona, la regulación urbanística de las viviendas turísticas en Bilbao ha sido avalada sin objeciones por el TSJPV y el TS. En el caso de Bilbao también se establecen limitaciones por zonas, además de otras en relación con la posición de la vivienda turística dentro del edificio. En Bilbao las viviendas turísticas son calificadas como equipamiento, lo que permite diferenciarlas claramente del uso residencial, y por ello la jurisprudencia entiende que está plenamente justificado el doble régimen de control administrativo: declaración responsable por la vía de la legislación turística e informe urbanístico de conformidad con el planeamiento urbanístico.

En ambas ciudades la aplicación del citado planeamiento limitativo ha configurado de facto, en las zonas céntricas de las ciudades, un régimen de monopolio de carácter indefinido para los actuales titulares de los títulos habilitantes para ejercer la actividad.

Partiendo de esta realidad, creo necesario plantearse una adecuación del actual marco legislativo que avance hacia un régimen más respetuoso con los artículos 11 y 12 de la Directiva de Servicios y con el 8.1 de la Ley 17/2009, que garantice que este número limitado de títulos habilitantes -allí donde está justificado por razones urbanísticas- tienen una duración limitada y que en el procedimiento de concesión se garantiza el cumplimiento de los principios de publicidad, objetividad, imparcialidad, transparencia y concurrencia competitiva. De hecho, la temporalidad de la declaración responsable de vivienda turística es una previsión que actualmente ya contempla la Ley 8/2012, de 19 de julio, del turismo de las Illes Balears, justamente por razones urbanísticas.

Este nuevo modelo, además, tiene el gran reto de incorporar en él a los títulos habilitantes existentes sin tener que asumir la indemnización de su extinción. Por ello sería necesario prever un régimen transitorio en esta nueva legislación, con un plazo razonable, para exigir que los actuales titulares de viviendas turísticas -en ciudades con los títulos limitados urbanísticamente- se adaptaran a la nueva regulación o se extinguieran sus títulos. Este régimen transitorio podría operar como un mecanismo indemnizatorio de los títulos a extinguir, de conformidad con lo previsto en el artículo 32.3 de la Ley 40/2015, de 1 de octubre, de Régimen Jurídico del Sector Público, que dispone la posibilidad de que el propio acto legislativo regule la forma de indemnizar la lesión causada por el mismo (Moret et al., 2017, 27-34) ${ }^{37}$.

Con todo ello se garantizaría que el mercado de las viviendas turísticas, allí donde justificadamente se limitase por el planeamiento a un número concreto de títulos, no quedase en régimen de monopolio de los titulares de los títulos habilitantes existentes. Se trataría de compatibilizar así las exigencias de las razones imperiosas de interés general, que justifican limitar las viviendas de uso turístico, y al mismo tiempo garantizar un escrupuloso respeto a las reglas de la Directiva de Servicios y su normativa de desarrollo.

El derecho a una vivienda digna o el derecho a la ciudad (Gifreu, 2020, 29-58) no deben ser obstáculo -ni pretexto- para impedir el correcto desarrollo de la libertad de prestación de servicios.

\section{REFERENCIAS BIBLIOGRÁFICAS}

Arana García, E. (2018). La intervención local en las viviendas de uso turístico a través de la zonificación urbanística: requisitos y consecuencias. REALA, 10, 6-21. https://doi.org/10.24965/reala.v0i10.10545

Artigot Golobardes, M. (2017). Retos de las viviendas turísticas en Barcelona: entre el mercado y la regulación. Papeles de Economía Española, 151, 189-206. http://dx.doi.org/10.2139/ssrn.2957677

Atxukarro Arruabarrena, I. (2017). La regulación urbanística de las viviendas para uso turístico. El Consultor de los ayuntamientos y los juzgados, 12, 1.598-1.604.

Atxukarro Arruabarrena, I. (2019). El urbanismo, el libre acceso a las actividades de servicios y su ejercicio, y el derecho de la competencia: usos urbanísticos y ejercicio de actividades en edificios residenciales. El caso de las viviendas turísticas. Práctica Urbanística: Revista Mensual de Urbanismo, 159, 1-29.

Autoritat Catalana de la Competència (ACCO) (diciembre de 2014). Recomendaciones sobre la regulación detallada de los usos del suelo desde la óptica de la competencia (ref. núm. ES 8/2014). http://acco.gencat.cat/web/. content/80_acco/documents/arxius/actuacions/ES_8_2014_USOS_DEL_SOL_CAT.pdf

37 Esta vía, aunque criticada por la doctrina (Doménech, 2019, 11), fue la escogida en su momento por la Ley de Costas, para evitar indemnizar a las propiedades privadas que se incorporaban al dominio público marítimo terrestre -validada posteriormente por la STC 149/1991, de 4 de julio- y mucho más recientemente por el Real Decreto-ley 13/2018, de 28 de septiembre, por el que se modifica la Ley de Ordenación de los Transportes Terrestres en materia de arrendamiento de vehículos con conductor, que establecía un régimen transitorio para indemnizar a los titulares de autorizaciones que se extinguían con la nueva regulación. Sobre las «expropiaciones regulatorias» también se puede leer a Gabriel Doménech (2012, 1-60). 
REALA. Nueva Época - N. ${ }^{15}$, abril 2021 - ISSN: 1989-8975 - DOI: https://doi.org/10.24965/reala.i15.10916 - [Págs. 24-41]

La regulación municipal de las viviendas de uso turístico: soluciones a través del urbanismo Josep M. Aguirre i Font

Autoritat Catalana de la Competència (ACCO) (13 de julio de 2017). Nota sobre la aprobación definitiva del Plan especial urbanístico de alojamientos turísticos (PEUAT) de Barcelona (ref. OB 33/2017). http://acco.gencat.cat/ web/.content/80 acco/documents/arxius/actuacions/20170720 OB-33-2017-Nota-PEUAT- CAST.pdf

Autoridad Vasca de la Competencia (AVC) (2018). Informe sobre la ordenanza reguladora del uso urbanístico de vivienda turística y alquiler de habitaciones en vivienda habitual para uso turístico del Ayuntamiento de San Sebastián [Proyecto LEA/AVC, núm. 250-PROM-2017]. https://www.competencia.euskadi.eus/contenidos/ informacion/informes/es_informes/adjuntos/250_INFORME_ORDENACION_URBANA_DONOSTIA_web_es.pdf

Bauzá Martorell, F. J. (2018). Intervención administrativa en la vivienda turística vacacional. Revista Española de Derecho Administrativo, 189, 313-346.

Boix Palop, A. (2018). Economía colaborativa para el desarrollo local. En M. R. Alonso Ibáñez (dir.), La sostenibilidad socioeconómica de las ciudades: estudios jurídicos (pp. 369-409). Tirant lo Blanch.

Comisión Nacional de los Mercados y la Competencia (CNMC) (2018). Estudio sobre las viviendas de uso turístico en España (ref. E/CNMC/003/18). CNMC. https://www.cnmc.es/expedientes/ecnmc00318

Cuscó Puigdellívol, E. y Font Garolera, J. (2015). Nuevas formas de alojamiento turístico: comercialización, localización y regulación de las viviendas de uso turístico en Cataluña. Biblio3W: Revista Bibliográfica de Geografía y Ciencias Sociales, 20(1.134). https://doi.org/10.1344/b3w.0.2015.26123

Doménech Pascual, G. (2012). Cómo distinguir entre una expropiación y una delimitación de la propiedad no indemnizable. InDret. Revista para el Análisis del Derecho, 1/2012. https://www.raco.cat/index.php/InDret/article/ view/260792

Doménech Pascual, G. (2018). La regulación autonómica y local de las viviendas de uso turístico. En Anuario de Derecho Municipal 2017 (número 11, pp. 43-73). Marcial Pons.

Doménech Pascual, G. (2019). Penalty y expulsión. La economía de las plataformas digitales en el sector de los taxis y los VTC. En A. Ortí Vallejo y G. Rubio Gimeno (eds.), Propuestas de regulación de las plataformas de economía colaborativa. Perspectivas general y sectoriales. Aranzadi.

Duatis, J., Buhigas, M. y Cruz, H. (2016). Impacte del lloguer vacacional en el mercat de lloguer residencial de Barcelona. Ajuntament de Barcelona.

Exceltur (25 de junio de 2015). Alojamiento turistico en viviendas de alquiler: impactos y retos asociados. Impactos sociales y económicos sobre los destinos españoles derivados del exponencial aumento del alquiler de viviendas turísticas de corta duración, impulsado por los nuevos modelos y canales de comercialización P2P. Recuperado de https://www.exceltur.org/monograficos/alojamiento-turistico/

García López, M. À., Jofre Monseny, J., Martínez Mazza, R. y Segú, M. (2020). Do short-term rent platforms affect housing markets? Evidence from Airbnb in Barcelona. Journal of Urban Economics, 119, (artículo 103.278). https:// doi.org/10.1016/j.jue.2020.103278

Gifreu Font, J. (2020). Derecho a la ciudad, ¿un sumatorio de derechos citadinos o un derecho independiente? En C. Barrero Rodríguez y J. M. Socías Camacho (coords.), La ciudad del siglo XXI: Transformaciones [Actas del XV Congreso de la Asociación Española de Profesores de Derecho Administrativo (AEPDA)] (pp. 29-58). INAP.

Guillén Navarro, N. A. (2015). La vivienda de uso turístico y su incidencia en el panorama normativo español. Revista Aragonesa de Administración Pública, 45-46, 101-144. http://bibliotecavirtual.aragon.es/bva/i18n/catalogo_ imagenes/grupo.cmd?path $=3712844$

Herrero Suárez, C. (2017). Las viviendas de uso turístico: ¿el enemigo a abatir? Reflexiones sobre la normativa autonómica en materia de alojamientos turísticos. Revista de Estudios Europeos, 70, 147-158. http://www.ree-uva. es/index.php/sumarios/2017/n-70-julio-diciembre-2017/106

INE, Instituto Nacional de Estadística (2020). Medición del número de viviendas turísticas en España y su capacidad. https://www.ine.es/experimental/viv_turistica/experimental_viv_turistica.htm

Moret Millás, V. y Gatóo Jimenez de Laiglesia, S. (2017). Lā responsabilidad del Estado-legislador, antecedentes y situación tras la reforma de 2015. Revista de las Cortes Generales, 100-102, 7-46. https://doi.org/10.33426/ rcg/2017/100-102/26

Otero Oitavén, M. M. (2020). El planificador urbanístico ante el reto de la ordenación de las viviendas de uso turístico. Legitimidad y oportunidad. En C. Barrero Rodríguez y J. M. Socías Camacho (coords.), La ciudad del siglo XXI: Transformaciones [Actas del XV Congreso de la Asociación Española de Profesores de Derecho Administrativo (AEPDA)] (pp. 285-293). INAP.

Roca Cladera, J. (dir.) (2016). Informe sobre la incidència de l'activitat turística en l'accessibilitat a l'habitatge a Barcelona. Centre de Política del Sòl i Valoracions - UPC. https://ajuntament.barcelona.cat/informaciourbanistica/ cerca/es/fitxa/B1463/--/--/ap/

Rodríguez Florido, I. (2020). La regulación del alojamiento turístico en Barcelona: el PEUAT y los distintos pronunciamientos judiciales recaídos sobre su legalidad. Revista Aranzadi de Urbanismo y Edificación, 45, 295-312.

Rodríguez Font, M. (2016). La regulació de l'allotjament col·laboratiu a Catalunya: anàlisi de les propostes de l'Autoritat Catalana de la Competència. en Revista Catalana de Dret Públic, 53, 163-181. http://dx.doi.org/10.2436/rcdp. i53.2016.2847 
REALA. Nueva Época - N. ${ }^{\circ}$ 15, abril 2021 - ISSN: 1989-8975 - DOI: https://doi.org/10.24965/reala.i15.10916 - [Págs. 24-41]

La regulación municipal de las viviendas de uso turístico: soluciones a través del urbanismo

Josep M. Aguirre i Font

Román Márquez, A. (2018). Planificación urbanística del turismo: la regulación de las viviendas de uso turístico en Madrid y Barcelona. Revista de Estudios de la Administración Local y Autonómica. Nueva época (REALA), 10, 2239. https://doi.org/10.24965/reala.v0i10.10566

Román Sánchez, I. M., Paulova, N., Nieto González, J. L. y Bonillo Muñoz, D. (2017). La legislación sobre los apartamentos turísticos y viviendas de uso turístico en España, comparativa por comunidades autónomas. International Journal of Scientific Management and Tourism, 3(4), 397-417. http://www.ijosmt.com/index.php/ ijosmt/article/view/296

Socías Camacho, J. M. (2018). Estado regulador y alojamiento colaborativo. El régimen de la intervención pública limitadora de la prestación del servicio. Revista de Administración Pública, 205, 131-170. https://doi.org/10.18042/ cepc/rap.205.04

Socías Camacho, J. M. (2020). Espacio público en la ciudad turística. En C. Barrero Rodríguez y J. M. Socías Camacho (coords.), La ciudad del siglo XXI: Transformaciones [Actas del XV Congreso de la Asociación Española de Profesores de Derecho Administrativo (AEPDA)] (pp. 225-257). INAP. 